\title{
Re-evaluating the clinical significance of serum p53 antibody levels in patients with oral cancer in Japanese clinical practice
}

\author{
SHUNSUKE GOHARA ${ }^{1}$, RYOJI YOSHIDA ${ }^{1}$, KENTA KAWAHARA ${ }^{1}$, JUNKI SAKATA $^{1}$, HIDETAKA ARITA ${ }^{1}$, \\ HIKARU NAKASHIMA ${ }^{1}$, SHO KAWAGUCHI ${ }^{1}$, YUKA NAGAO ${ }^{1}$, KEISUKE YAMANA ${ }^{1}$, MASASHI NAGATA ${ }^{1}$, \\ AKIYUKI HIROSUE $^{1}$, AKIMITSU HIRAKI ${ }^{2}$ and HIDEKI NAKAYAMA ${ }^{1}$
}

${ }^{1}$ Department of Oral and Maxillofacial Surgery, Faculty of Life Sciences, Kumamoto University, Kumamoto 860-8556;
${ }^{2}$ Section of Oral Oncology, Department of Oral and Maxillofacial Surgery, Fukuoka Dental College, Fukuoka 814-0193, Japan

Received January 14, 2021; Accepted June 1, 2021

DOI: $10.3892 / \mathrm{mco} .2021 .2372$

\begin{abstract}
TP53 gene mutations can lead to mutant p53 protein accumulation in cancer cells, thereby inducing the production of serum antip53 antibodies (Ap53Ab) in patients with various types of cancer. The aim of the present study was to re-evaluate the clinicopathological and prognostic significance of Ap53Ab using the Ap53Ab ELISA kit, approved by the Japanese Health Insurance System in 2007. Ap53Ab was measured as a tumor marker in 94 patients with oral squamous cell carcinoma (OSCC), by subjecting paraffin-embedded sections obtained from biopsy specimens to immunohistochemical analysis to confirm p53 expression. The associations among Ap53Ab status, p53 expression and clinical significance in OSCC were examined. A total of $23 \%$ of the patients were Ap53Ab-positive. $\mathrm{Ap} 53 \mathrm{Ab}$ status was found to be significantly associated with p53 expression status in primary tumors $(\mathrm{P}=0.027)$, clinical T-category, pathological $\mathrm{N}$-category and pathological stage ( $\mathrm{P}=0.04, \mathrm{P}=0.010$ and $\mathrm{P}=0.013$, respectively). Kaplan-Meier curve analysis revealed that Ap53Ab status was significantly associated with poor disease-free survival (DFS; $\mathrm{P}=0.043$ ), and Cox regression analysis revealed that Ap53Ab status was a significant prognostic factor for DFS in patients with OSCC (hazard ratio $=2.807 ; 95 \%$ confidence interval: 1.029-7.160; $\mathrm{P}=0.044)$. These results suggested that Ap53Ab measurement may reflect the p53 mutation status and an aggressive
\end{abstract}

Correspondence to: Dr Ryoji Yoshida, Department of Oral and Maxillofacial Surgery, Faculty of Life Sciences, Kumamoto University, Honjo 1-1-1, Chuo-ku, Kumamoto 860-8556, Japan E-mail: ryoshida@kumamoto-u.ac.jp

Abbreviations: Ap53Ab, serum antip53 antibodies; OSCC, oral squamous cell carcinoma; cT-category, clinical T-category; cN-category, clinical T-category; pT-category, pathological T-category; pN-category, pathological N-category; OS, overall survival; DFS, disease-free survival; HR, hazard ratio; CI, confidence interval

Key words: oral squamous cell carcinoma, serum p53 antibody, prognosis; TP53, mutation malignant phenotype, and it may serve as a useful predictive marker candidate for OSCC in clinical practice.

\section{Introduction}

Oral cancer is the most common malignant tumor in the oral cavity and its survival rate has not improved, despite innovations in diagnostic techniques and treatments (1). In general practice, various serum tumor markers have been found to be useful for the screening of cancer and for determining the degree of progression, evaluating therapeutic efficacy, and predicting the prognosis, recurrence and metastasis, and they are currently employed for prostate, lung and liver cancer. However, although the squamous cell carcinoma antigen (SCC Ag) is used as a tumor marker in general practice (2), there are currently no suitable diagnostic biomarkers for oral squamous cell carcinoma (OSCC) to the best of our knowledge. Therefore, it is necessary to investigate reliable serum tumor markers for routine OSCC diagnosis.

The serum antip53 antibody (Ap53Ab) is an $\mathrm{IgG}$ antibody that reacts with the $\mathrm{p} 53$ protein that accumulates in the nucleus as a result of mutations in the TP53 tumor suppressor gene, which exhibits the highest mutation frequency among malignant tumors (3). Unlike other conventional tumor markers that detect tumor cell-derived proteins, Ap53Ab has been considered as an innovative tumor marker, in the sense that it detects serum antibodies that emerge in response to tumor cell-derived proteins (4). Ap53Ab triggers an antigen-antibody reaction, which is positive even in the early stages of cancer, and can detect micro-residual tumor cells after treatment $(5,6)$. As a result of the remarkable results of a study by Shimada et al (7), the measurement of Ap53Ab levels has been covered from 2007 onwards by medical insurance in Japan for esophageal, colorectal and breast cancer, and can be applied to daily clinical practice. Although several studies have investigated the expression of Ap53Ab in OSCC $(2,8,9)$, to the best of our knowledge, there have been no reports on measuring Ap53Ab in daily clinical practice, despite the need to re-evaluate the clinicopathological significance of Ap53Ab in oral cancer.

The prognostic significance of Ap53Ab (as measured by an ELISA kit approved by the Japanese Health Insurance System in 2007) has been revalidated and reported for several 
malignancies, such as esophageal, liver, gastric and colorectal cancer (10-12). Although a relatively high positive rate was reported by Shimada et al (7), no studies have yet evaluated the utility of Ap53Ab measurement in daily clinical practice as a prognostic marker for head and neck cancer, including OSCC. Given that TP53 mutations occur frequently and that these mutations adversely affect the malignant phenotype (13), it is important to re-evaluate the utility of Ap53Ab as a prognostic factor for Japanese patients with OSCC in clinical practice.

The present study was undertaken to revalidate the detection rate of Ap53Ab and examine the correlation between $\mathrm{Ap} 53 \mathrm{Ab}$ status and $\mathrm{p} 53$ expression in primary OSCC, and to re-evaluate the clinical significance of Ap53Ab in OSCC.

\section{Materials and methods}

Patients. The study population comprised 94 patients with OSCC who underwent radical resection as primary treatment at the Kumamoto University Hospital (Kumamoto, Japan) between April 2015 and March 2018. The median age of the study population was 66.8 years (range, 24-88 years). Of the 94 patients, 57 were male and 37 were female. The primary tumors were located in the tongue $(\mathrm{n}=51)$, maxilla $(\mathrm{n}=5)$, mandible $(\mathrm{n}=21)$, hard palate $(n=1)$, oral floor $(n=9)$ and buccal mucosa $(n=7)$. The clinical T-category (cT-category) was recorded as cT1, cT2, cT3 and cT4a in 21, 50, 13 and 10 patients, respectively. The clinical $\mathrm{N}$-category (cN-category) was recorded as $\mathrm{cN} 0, \mathrm{cN} 1, \mathrm{cN} 2 \mathrm{~b}$, $\mathrm{cN} 2 \mathrm{c}$ and $\mathrm{cN} 3 \mathrm{~b}$ in 73, 7, 12, 1 and 1 patients, respectively. The clinical stage (cStage) was recorded as I-III and IV in 21, 42, 14 and 17 patients, respectively. The pathological T-category (pT-category) was recorded as pT1, pT2, pT3 and pT4a in 19, 55, 14 and 6 patients, respectively. The pathological $\mathrm{N}$-category (pN-category) was recorded as $\mathrm{pN} 0, \mathrm{pN} 1, \mathrm{pN} 2 \mathrm{~b}, \mathrm{pN} 2 \mathrm{c}$ and $\mathrm{pN} 3 \mathrm{~b}$ in $84,4,2,2$ and 2 patients, respectively. Finally, the pathological stage (pStage) was recorded as I-III and IV in 19, 52, 12 and 11 patients, respectively. Patients who had distant metastases prior to treatment initiation were excluded from the present study. The patients were diagnosed based on histological and radiological findings, including computed tomography, magnetic resonance imaging, ultrasonography and positron emission tomography-computed tomography findings. All tumors were staged according to the 8th edition of the TNM classification of the American Joint Committee on Cancer (14), and the differentiation was determined according to the World Health Organization classification (15). The worst pattern of invasion was recorded as follows: Non-aggressive patterns included broad pushing margin (WPOI-1), broad finger-like projections or separate large islands (WPOI-2), and those exhibiting invasive islands ( $>15$ cells; WPOI-3). Aggressive patterns included WPOI-4, with islands of $<5$ cells, strands of tumor cells or single-cell infiltration, and WPOI-5, exhibiting tumor satellites separated from the main tumor interface by $>1 \mathrm{~mm}$. After undergoing curative surgery, the patients were followed up until March 2020. The study was conducted with the approval of the Ethics Committee of Kumamoto University (approval no. RINRI:1427), in accordance with the guidelines for Good Clinical Practice and the Declaration of Helsinki. The present study was a retrospective analysis, which does not require individual consent; however, it guarantees inclusion in the study and offers the opportunity to refuse participation in an opt-out format (RINRI1427).
Blood samples and Ap53Ab measurement. Total blood samples $(5 \mu \mathrm{l})$ were routinely collected from the patients with OSCC prior to surgery. The titers of Ap53Ab were assessed using an ELISA kit (MESACUP anti-p53 Test; cat. no. 7640E, Medical \& Biological Laboratories, Co., Ltd.). Briefly, samples were added to microtiter plate wells coated with either wild-type human p53 or control protein and incubated for $1 \mathrm{~h}$. Peroxidase-conjugated goat anti-human immunoglobulin G-binding Ap53Ab was then added, followed by incubation for $1 \mathrm{~h}$. Thereafter, substrate solution was added, followed by incubation for $30 \mathrm{~min}$. A calibration curve was constructed from specific signals of standards and from the levels of antibodies indicated on the vials containing the standards. To ensure the accuracy of the test, researchers blinded to the clinical data of the patient performed the measurements together with a laboratory specialist. Considering that the cutoff value of $\mathrm{Ap} 53 \mathrm{Ab}$ has generally been set to $1.3 \mathrm{U} / \mathrm{ml}$ for other malignant tumors in daily clinical practices across Japan, the present study adopted the same cutoff value.

Immunohistochemical (IHC) staining and assessment. Formalin-fixed, paraffin-embedded specimens were cut into 4- $\mu \mathrm{m}$ sections and mounted on MAS-GP-coated slides (Matsunami Glass Ind., Ltd.). To retrieve the p53 antigen, the sections were subjected to deparaffinization and rehydration, and then heated in an autoclave in $0.01 \mathrm{~mol} / \mathrm{l}$ citrate buffer (pH 7.0) for $15 \mathrm{~min}$ at $121^{\circ} \mathrm{C}$. The sections were subsequently incubated with $3 \%$ hydrogen peroxide in absolute methanol for 15 min to block endogenous peroxidase activity. The sections were also incubated with Protein Block Serum-Free Reagent (Dako; Agilent Technologies, Inc.) at room temperature for 10 min to block non-specific staining. After the blocking step, the sections were incubated at $4^{\circ} \mathrm{C}$ overnight with an anti-p53 antibody (1:100; clone DO-1, cat. no. sc-126, Santa Cruz Biotechnology, Inc.; 1:100; clone PAb240, cat. no. ab26, Abcam), followed by sequential 60-min incubations with the secondary antibody (EnVision + System-HRP Labelled Polymer, cat. no. K4000 or 4002, Dako; Agilent Technologies, Inc.) and the Liquid DAB+ Substrate Chromogen System (Dako; Agilent Technologies, Inc.). All slides were counterstained using hematoxylin at room temperature for $60 \mathrm{sec}$ before the dehydration and mounting steps. Two independent observers, who were blinded to the patients' clinical status, interpreted the IHC data. Based on previous reports (16-18), tumor samples with $>10 \%$ of tumor cells exhibiting positive nuclear staining were considered to be positive for p53. Disagreements regarding the IHC staining scores were resolved through discussion and consensus.

Statistical analysis. Fisher's exact test was employed for categorical factors to calculate the P-values indicating the significance of the associations between the Ap53Ab status and clinicopathological factors. The pre-treatment values of Ap53Ab were not normally distributed according to the $\chi^{2}$ goodness-of-fit test. Therefore, the Kruskal-Wallis and Bonferroni-Dunn tests were used to evaluate differences between the pre-treatment values of Ap53Ab for each clinical stage. Survival analysis was performed using the Kaplan-Meier method and the log-rank test and multivariate survival analyses were performed using Cox regression models to evaluate the association between Ap53Ab status and overall survival (OS) 
Table I. Changes in serum antip53 antibody titer among the 23 patients with oral squamous cell carcinoma after surgery.

\begin{tabular}{|c|c|c|c|}
\hline $\begin{array}{l}\text { Case } \\
\text { no. }\end{array}$ & $\begin{array}{l}\text { Before } \\
\text { surgery }\end{array}$ & $\begin{array}{c}\text { After } \\
\text { surgery }\end{array}$ & $\begin{array}{l}\text { Type of } \\
\text { change }\end{array}$ \\
\hline 4 & 5.05 & 4.61 & Decrease \\
\hline 6 & 3.00 & 3.49 & Increase \\
\hline 13 & 2.62 & 2.49 & Decrease \\
\hline 21 & 2.05 & 1.48 & Decrease \\
\hline 22 & 2.20 & 1.83 & Decrease \\
\hline 26 & 0.84 & 1.19 & Increase \\
\hline 31 & 0.23 & 0.76 & Increase \\
\hline 32 & 0.53 & 0.56 & Increase \\
\hline 37 & 0.87 & 0.34 & Decrease \\
\hline 39 & 1.43 & 1.56 & Increase \\
\hline 40 & 6.28 & 0.79 & Decrease \\
\hline 53 & 1.01 & 1.22 & Increase \\
\hline 64 & 3.56 & 3.98 & Increase \\
\hline 65 & 2.79 & 2.34 & Decrease \\
\hline 66 & 1.02 & 1.00 & Decrease \\
\hline 67 & 35.50 & 33.20 & Decrease \\
\hline 68 & 0.86 & 0.71 & Decrease \\
\hline 71 & 0.62 & 0.88 & Increase \\
\hline 73 & 0.63 & 1.02 & Increase \\
\hline 74 & 0.79 & 1.25 & Increase \\
\hline 77 & 1.32 & 1.01 & Decrease \\
\hline 93 & 1.26 & 1.20 & Decrease \\
\hline 94 & 0.95 & 0.94 & Decrease \\
\hline
\end{tabular}

and disease-free survival (DFS). All P-values were based on two-tailed tests, and $\mathrm{P}<0.05$ were considered to indicate statistically significant differences. All statistical analyses were performed using JMP software version 9 (SAS Institute Inc.).

\section{Results}

Rate of Ap53Ab positivity in the study population. To determine the Ap53Ab positivity rate in patients with OSCC, the $\mathrm{Ap} 53 \mathrm{Ab}$ values in the study population were reviewed. The cutoff value was set at $1.3 \mathrm{U} / \mathrm{ml}$, which is employed in daily clinical practice in Japan. Of the 94 patients with OSCC, 23 (23.4\%) were Ap53Ab-positive. The mean Ap53Ab level $( \pm \mathrm{SD})$ in patients with OSCC was $1.08 \pm 6.75 \mathrm{U} / \mathrm{ml}$ (range, 0.2-37.8 U/ml). The Ap53Ab levels tended to increase with advancing clinical stage, although the differences among different stages were not statistically significant (Fig. 1). Moreover, a decrease in Ap53Ab level was observed in 13 of the 23 patients $(56.5 \%)$ whose Ap53Ab levels were measurable prior to surgery. In particular, among the 11 patients positive for Ap53Ab (>1.3 U/ml) prior to surgery, 8 exhibited a decrease in the Ap53Ab titer postoperatively (72.7\%; Table I).

Associations between Ap53Ab status and IHC staining results of p53. To examine the association between Ap53Ab status and the expression patterns of mutated p53 in the primary tumors,
Table II. Association between Ap53Ab status and results of p53 immunohistochemical staining in 96 patients with oral squamous cell carcinoma.

\begin{tabular}{lccc}
\hline & \multicolumn{2}{c}{ Ap53Ab status } & \\
\cline { 2 - 3 } & $\begin{array}{c}\text { Negative, } \\
\text { Antibody }\end{array}$ & $\begin{array}{c}\text { Positive, } \\
\mathrm{n}(\%)\end{array}$ & P-value \\
\hline Total (n=94) & $72(76.6)$ & $22(23.4)$ & \\
DO-1 & & & 0.027 \\
Negative & $41(56.9)$ & $6(27.3)$ & \\
Positive & $31(43.1)$ & $16(72.7)$ & \\
Pab240 & & & 0.126 \\
Negative & $50(69.4)$ & $11(50.0)$ & \\
Positive & $22(30.6)$ & $11(50.0)$ & \\
Either DO-1- or & & & \\
Pab240-positive & & & \\
No & $38(52.8)$ & $8(36.4)$ & \\
Yes & $34(47.2)$ & $14(63.6)$ & \\
\hline
\end{tabular}

Fisher's exact test for categorical factors was used to calculate P-values between Ap53Ab status and the results of immunohistochemical staining in the primary tumor. Ap53Ab, serum anti-p53 antibody.

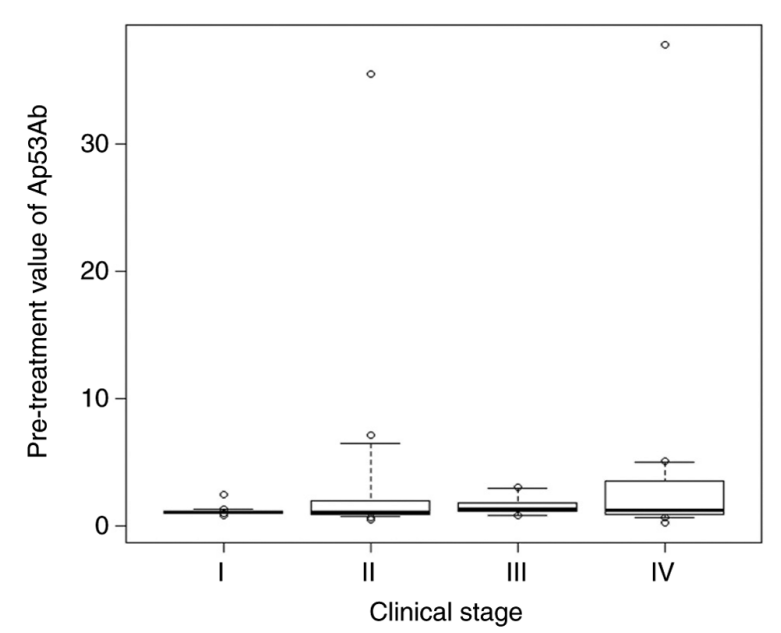

Figure 1. Serum Ap53Ab values across each clinical stage. Box plot showing pretreatment Ap53Ab values across each clinical stage. The y-axis shows the mean Ap53Ab values. The bold line in the center of the boxplot indicates the median. The top and the bottom of the box represent the third and first quartiles, respectively. The upper and lower whiskers refer to the largest and smallest data points, respectively, in the range between (1st quartile-1.5 x IQR) and (3rd quartile + 1.5 x IQR) in the default settings. Circles represent outliers. Ap53Ab, anti-p53 antibody; IQR, interquartile range.

IHC staining of p53 was performed by using the clones DO-1 and PAb240, which are representative clones for detecting TP53 mutations. The representative immunostaining patterns of p53 for each clone are shown in Fig. 2A and B. A total of $47(50.0 \%)$ of the 94 patients with OSCC were positive for DO-1, while $33(35.1 \%)$ were positive for PAb240. In addition, 48 patients $(51.1 \%)$ were positive for either DO-1 or PAb240 (Table II). There was a significant correlation between Ap53Ab 
A
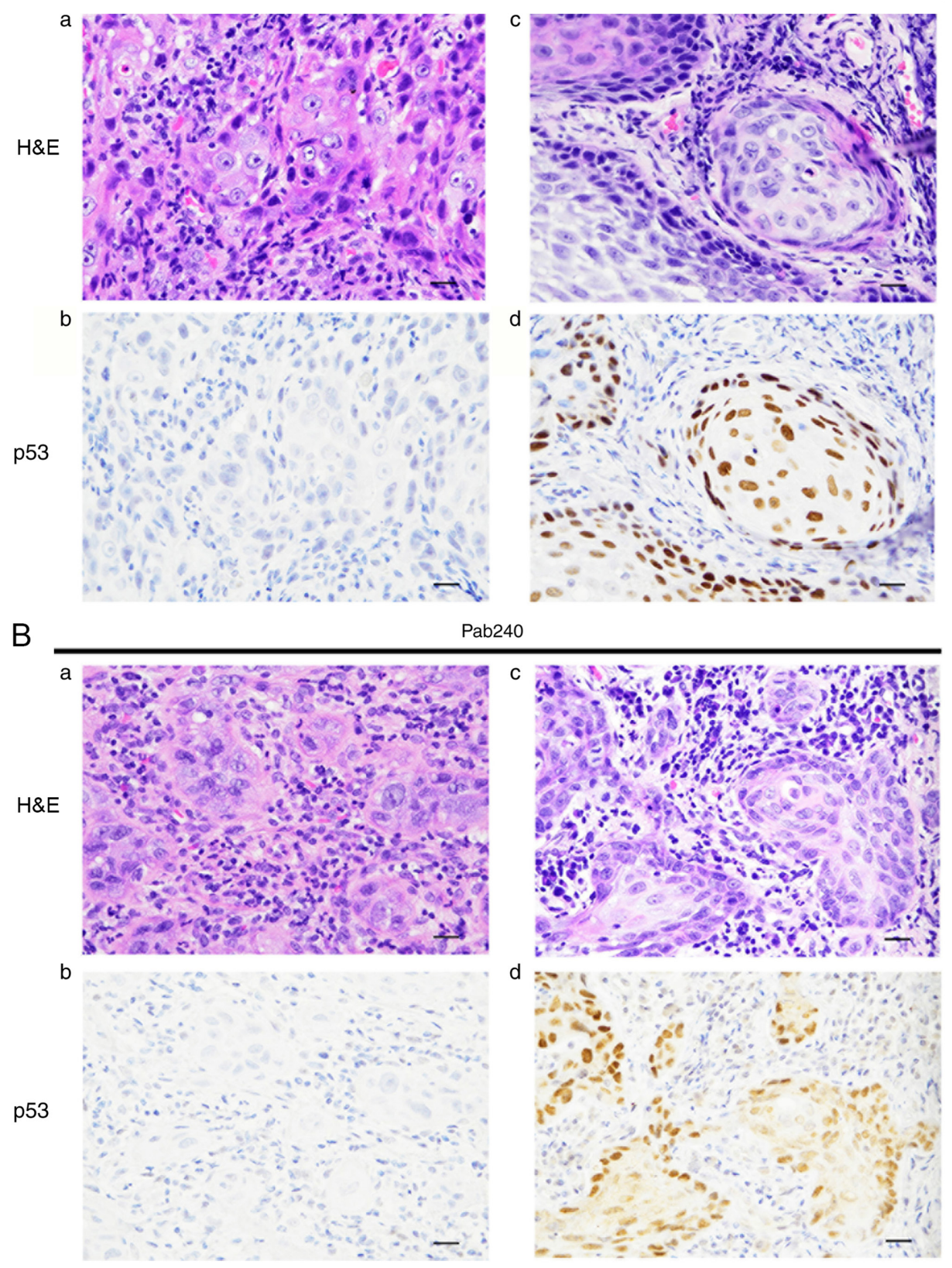

Figure 2. Representative images showing the results of HE and IHC staining of p53 in clinical samples. (A) Representative images showing the results of HE and IHC staining of p53 using clone DO-1. Representative (a) HE and (b) IHC staining in p53-negative tissue. Representative (c) HE and (d) IHC staining in p53-positive tissue. Original magnification, x400; scale bar, $20 \mu \mathrm{m}$. (B) Representative images showing the results of HE and IHC staining of p53 using clone PAb240. Representative (a) HE and (b) IHC staining in p53-negative tissue. Representative (c) HE and (d) IHC staining in p53-positive tissue. Original magnification, $\mathrm{x} 400$; scale bar, $20 \mu \mathrm{m}$. IHC, immunohistochemical.

status and p53 staining pattern, which could be detected by the DO- 1 clone expression status in primary tumors $(\mathrm{P}=0.027$; Table II).

Associations between Ap53Ab status and clinicopathological characteristics. To elucidate the clinical significance of the Ap53Ab status in the 94 patients with OSCC, the correlations between Ap53Ab status and the clinicopathological variables were examined. The clinical background characteristics of the study patients were divided into two groups, namely Ap53Ab-positive and Ap53Ab-negative (Table III). The frequency of Ap53Ab positivity was significantly higher in patients with advanced cT-category, $\mathrm{pN}$-category and pStage ( $\mathrm{P}=0.04, \mathrm{P}=0.010$ and $\mathrm{P}=0.013$, respectively; Table III).

Associations between Ap53Ab status and prognosis. To assess the impact of Ap53Ab status on survival time, the DFS and OS of the 94 patients with OSCC were analyzed by using the Kaplan-Meier method. The 5-year DFS rates of patients with an Ap53Ab-positive status were significantly lower compared with those of patients with an Ap53Ab-negative status $(\mathrm{P}=0.043$; Fig. 3A). Conversely, there was no statistically significant difference in the 5-year OS rates ( $\mathrm{P}=0.579$; Fig. 3B). Moreover, the multivariate analysis using the Cox proportional 
Table III. Association between Ap53Ab status and clinicopathological factors in 94 patients with oral squamous cell carcinoma.

\begin{tabular}{|c|c|c|c|c|}
\hline \multirow[b]{2}{*}{ Characteristics } & \multirow[b]{2}{*}{ Total $(n=94)$} & \multicolumn{2}{|c|}{ Ap53Ab status } & \multirow[b]{2}{*}{ P-value } \\
\hline & & Negative, n (\%) & Positive, n (\%) & \\
\hline Total & & $72(76.6)$ & $22(23.4)$ & \\
\hline Age (years) & & & & 1.000 \\
\hline Median & 66.8 & 66.3 & 68.5 & \\
\hline Range & & $24-86$ & $45-88$ & \\
\hline$\leq 65$ & 33 & $25(34.7)$ & $8(36.4)$ & \\
\hline$>65$ & 61 & $47(65.3)$ & $14(63.6)$ & \\
\hline Sex & & & & 0.220 \\
\hline Male & 57 & $41(56.9)$ & $16(72.7)$ & \\
\hline Female & 37 & $31(43.1)$ & $6(27.3)$ & \\
\hline Oral subsite & & & & 0.901 \\
\hline Tongue & 51 & $40(55.6)$ & $11(50.0)$ & \\
\hline Oral floor & 9 & $6 \quad(8.3)$ & $3(13.6)$ & \\
\hline Mandible & 21 & $15(20.8)$ & $6(27.3)$ & \\
\hline Maxilla & 5 & 4 (5.6) & $1 \quad(4.5)$ & \\
\hline Buccal mucosa & 7 & $6(8.3)$ & $1(4.5)$ & \\
\hline Hard palate & 1 & 1 (1.4) & $0 \quad(0.0)$ & \\
\hline Clinical T-category & & & & $0.04^{\mathrm{a}}$ \\
\hline $\mathrm{T} 1$ & 21 & $19(26.4)$ & $2(9.1)$ & \\
\hline $\mathrm{T} 2$ & 50 & $40(55.6)$ & $10(45.5)$ & \\
\hline $\mathrm{T} 3$ & 13 & $8(11.1)$ & $5(22.7)$ & \\
\hline $\mathrm{T} 4$ & 10 & $5 \quad(6.9)$ & $5(22.7)$ & \\
\hline Clinical N-category & & & & 0.249 \\
\hline 0 & 73 & $58(80.6)$ & $15(68.2)$ & \\
\hline$\geq 1$ & 21 & $14(19.4)$ & 7 (31.8) & \\
\hline Clinical stage & & & & 0.077 \\
\hline I & 21 & $19(26.4)$ & $2(9.1)$ & \\
\hline II & 42 & $34(47.2)$ & $8(36.4)$ & \\
\hline III & 14 & $9(12.5)$ & $5(22.7)$ & \\
\hline IV & 17 & $10(13.9)$ & $7(31.8)$ & \\
\hline Pathological T-category & & & & 0.054 \\
\hline $\mathrm{T} 1$ & 19 & $17(23.6)$ & $2(9.1)$ & \\
\hline $\mathrm{T} 2$ & 55 & $44(61.1)$ & $11(50.0)$ & \\
\hline $\mathrm{T} 3$ & 14 & $8(11.1)$ & $6(27.3)$ & \\
\hline $\mathrm{T} 4$ & 6 & $3(4.2)$ & $3(13.6)$ & \\
\hline Pathological N-category & & & & $0.010^{\mathrm{a}}$ \\
\hline 0 & 84 & $68(94.4)$ & $16(72.7)$ & \\
\hline$\geq 1$ & 10 & 4 (5.6) & $6(27.3)$ & \\
\hline Pathological stage & & & & $0.013^{\mathrm{a}}$ \\
\hline I & 19 & $17(23.6)$ & $2(9.1)$ & \\
\hline II & 52 & $43(59.7)$ & $9(40.9)$ & \\
\hline III & 12 & 7 (9.7) & $5(22.7)$ & \\
\hline IV & 11 & $5 \quad(6.9)$ & $6(27.3)$ & \\
\hline Differentiation & & & & 0.361 \\
\hline High & 48 & $34(47.2)$ & $14(63.6)$ & \\
\hline Moderate & 42 & $34(47.2)$ & $8(36.4)$ & \\
\hline Poor & 4 & $4 \quad(5.6)$ & $0 \quad(0.0)$ & \\
\hline Worst pattern of invasion & & & & 0.335 \\
\hline $1^{\mathrm{b}}$ and $2^{\mathrm{c}}$ & 29 & $22(30.6)$ & $7(31.8)$ & \\
\hline $3^{\mathrm{d}}$ & 41 & $34(47.2)$ & $7(31.8)$ & \\
\hline $4^{\mathrm{e}}$ and $5^{\mathrm{f}}$ & 24 & $16(22.2)$ & $8(36.4)$ & \\
\hline
\end{tabular}


Table III. Continued.

\section{Ap53Ab status}

Characteristics

Total $(n=94)$

Negative, n (\%)

Positive, n (\%)

P-value

Local recurrence

No

84

$65(90.3)$

7 (9.7)

$19(86.4)$

10

64 (88.9)

$3(13.6)$

Delayed neck metastasis

$8(11.1)$

$17(77.3)$

12

$5(22.7)$

Yes

0.694
$67(93.1)$
$5(6.9)$
$20(90.9)$
13
$2(9.1)$
No

0.664

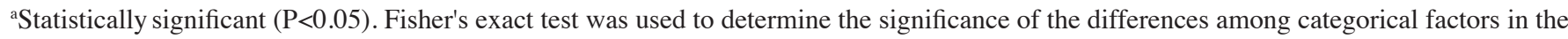
94 patients with OSCC. ${ }^{b}$ Broad pushing margin. ${ }^{~ B r o a d ~ f i n g e r-l i k e ~ p r o j e c t i o n s ~ o r ~ s e p a r a t e ~ l a r g e ~ i s l a n d s . ~}{ }^{\mathrm{d}}$ Invasive islands ( $>15$ cells). ${ }^{\mathrm{e}}$ Islands of $<5$ cells, strands of tumor cells or single-cell infiltration. ${ }^{\mathrm{f}}$ Tumor satellites separated from the main tumor interface by $>1 \mathrm{~mm}$. Ap53Ab, serum anti-p53 antibody.
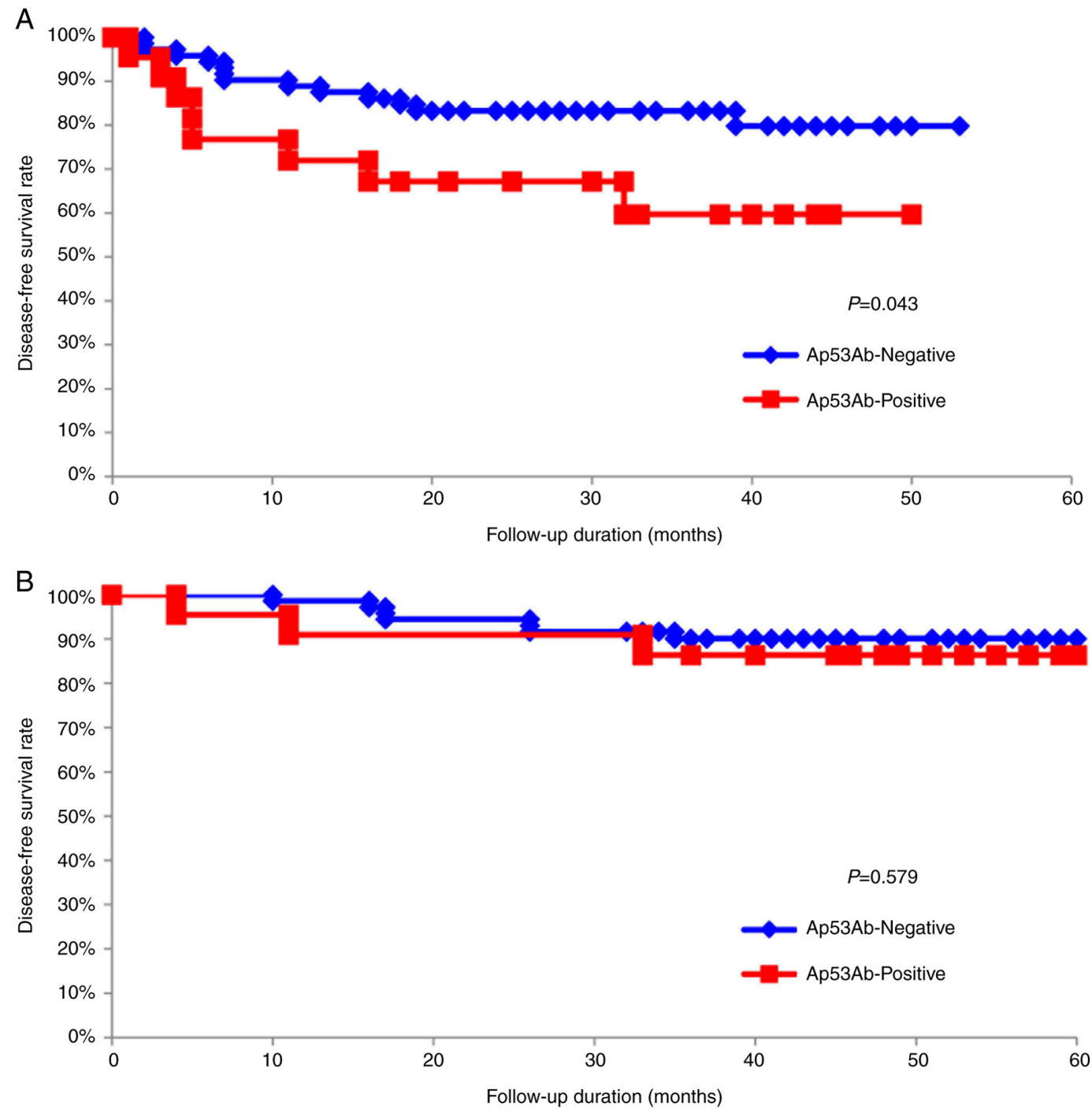

Figure 3. Association between Ap53Ab titer and survival in the overall cohort of patients with OSCC. Kaplan-Meier survival analysis of patients with OSCC divided into two groups based on Ap53Ab titers (negative and positive). (A) Disease-free and (B) overall survival of the 94 patients with OSCC based on Ap53Ab status. Ap53Ab, anti-p53 antibody; OSCC, oral squamous cell carcinoma. 
Table IV. Multivariate regression analysis results for predicting disease-free survival in 94 patients with oral squamous cell carcinoma.

\begin{tabular}{|c|c|c|c|}
\hline Variables & Assigned score & Hazard ratio $(95 \% \mathrm{CI})$ & P-value \\
\hline \multicolumn{4}{|c|}{ Ap53Ab status } \\
\hline Negative & 0 & \multirow[t]{2}{*}{$2.807(1.029-7.160)$} & \multirow[t]{2}{*}{$0.044^{\mathrm{a}}$} \\
\hline Positive & 1 & & \\
\hline \multicolumn{4}{|c|}{ Primary site } \\
\hline Tongue & 0 & \multirow[t]{2}{*}{$0.859(0.354-2.202)$} & \multirow[t]{2}{*}{0.761} \\
\hline Others & 1 & & \\
\hline \multicolumn{4}{|c|}{ Clinical T-category } \\
\hline $\mathrm{T} 1$ & 1 & \multirow[t]{4}{*}{$0.454(0.131-1.315)$} & \multirow[t]{4}{*}{0.148} \\
\hline $\mathrm{T} 2$ & 2 & & \\
\hline T3 & 3 & & \\
\hline $\mathrm{T} 4$ & 4 & & \\
\hline \multicolumn{4}{|c|}{ Clinical N-category } \\
\hline No & 1 & \multirow[t]{2}{*}{$0.176(0.035-0.678)$} & \multirow[t]{2}{*}{$0.012^{\mathrm{a}}$} \\
\hline$\geq \mathrm{N} 1$ & 2 & & \\
\hline \multicolumn{4}{|c|}{ Clinical stage } \\
\hline 1 & 1 & \multirow[t]{3}{*}{$4.412(1.065-20.529)$} & \multirow[t]{3}{*}{$0.041^{\mathrm{a}}$} \\
\hline 2 & 2 & & \\
\hline 3 and 4 & 3 & & \\
\hline \multicolumn{4}{|c|}{ Worst pattern of invasion } \\
\hline $1^{\mathrm{c}}$ and $2^{\mathrm{d}}$ & 1 & \multirow[t]{3}{*}{$3.579(1.816-7.665)$} & \multirow[t]{3}{*}{$<0.001^{\mathrm{b}}$} \\
\hline $3^{\mathrm{e}}$ & 2 & & \\
\hline $4^{\mathrm{f}}$ and $5^{\mathrm{g}}$ & 3 & & \\
\hline
\end{tabular}

Statistically significant: ${ }^{\mathrm{a}} \mathrm{P}<0.05,{ }^{\mathrm{b}} \mathrm{P}<0.01 .{ }^{\mathrm{c}} \mathrm{Broad}$ pushing margin. ${ }^{\mathrm{d}} \mathrm{Broad}$ finger-like projections or separate large islands. ${ }^{\mathrm{e}}$ Invasive islands ( $>15$ cells). Islands of $<5$ cells, strands of tumor cells or single-cell infiltration. ${ }^{\text {g}}$ Tumor satellites separated from the main tumor interface by $>1 \mathrm{~mm}$. Ap53Ab, serum anti-p53 antibody; CI, confidence interval.

hazards regression model on the 94 patients with OSCC revealed that the Ap53Ab status [hazard ratio $(\mathrm{HR})=2.807$; 95\% confidence interval (CI): 1.029-7.160; $\mathrm{P}=0.044]$, cN-category $(\mathrm{HR}=0.176 ; 95 \% \mathrm{CI}$ : $0.035-0.678 ; \mathrm{P}=0.012)$, cStage $(\mathrm{HR}=4.412 ; 95 \% \mathrm{CI}: 1.065-20.529 ; \mathrm{P}=0.041)$ and worst pattern of invasion $(\mathrm{HR}=3.579$; 95\% CI: 1.816-7.665; $\mathrm{P}<0.001)$ were significant prognostic factors for DFS (Table IV).

\section{Discussion}

From the late 1990 s to the early 2000 s, the seropositivity rate of p53 was reported to be $15-30 \%$ for head and neck SCC, including OSCC $(9,19-27)$. Although these results were based on the values obtained using ELISA, these reports were not the result of a unified kit. In other words, the differences in the Ap53Ab positivity rate may be attributed to the measuring equipment. In 2003, Shimada et al (7) reported a positive rate of $35 \%$ for Ap53Ab in head and neck SCC when using the MESACUP anti-p53Ab Test ELISA kit, which was approved by Japanese authorities and has since been covered by the Japan Health Insurance System. To make the study results universally applicable, the procedures must use test equipment that is employed in daily clinical practice. We therefore employed the MESACUP antip53Ab Test ELISA kit in the present study, resulting in an Ap53Ab positivity rate of $23 \%$, which was the same as that previously reported (7); however, to the best of our knowledge, this study is the first to collect data based on daily clinical practice in Japan specifically focusing on OSCC. Recently, Takahashi et al (28) reported decreased values in the majority of patients with colorectal cancer who were positive for $\mathrm{Ap} 53 \mathrm{Ab}(>1.3 \mathrm{U} / \mathrm{ml})$ after radical resection. The present results also demonstrated a decrease in Ap53Ab titers among the majority of patients following surgery, suggesting that Ap53Ab may be used as a monitoring marker in the future.

The wild-type p53 protein has a short half-life (20-30 min) and is rapidly degraded in cells, whereas the mutant p53 protein has a significantly longer degradation time (several hours) and accumulates in the nucleus. The mutant p53 protein can therefore be identified as protein overexpression using IHC. Conversely, the presence of the TP53 genetic abnormality may be inferred from protein overexpression. In line with previous reports $(8,25,29)$, a positive correlation between Ap53Ab status and p53 expression in the primary tumors was observed in the present study. Our results support the hypothesis that p53 accumulation in primary lesions may be involved in $\mathrm{p} 53$ autoantibody production, as proposed by various authors $(20,30,31)$. Other authors have reported that 10-30\% of cases harboring TP53 mutations (such as deletion, insertion, nonsense and splicing site mutations) show negative 
immunoreaction for p53 IHC staining (17,32-34). The data from the present study demonstrated that $\mathrm{p} 53$ overexpression in primary tumors was present in $\sim 70 \%$ of the patients with Ap53Ab positivity (Table II). Collectively, the findings of the present study indicate that Ap53Ab may also predict the expression status of p53 in primary OSCC, as well as in other malignancies. Moreover, the MESACUP antip53Ab Test ELISA kit could be employed as a less invasive diagnostic tool for determining the expression status of p53 (or the presence or absence of mutations) in OSCC. However, additional analyses are needed to elucidate the exact relationship between Ap53Ab status and TP53 mutational status in tumor samples.

There have been various reports on the correlation between $\mathrm{Ap} 53 \mathrm{Ab}$ and the clinical characteristics of head and neck SCC, including OSCC. Wollenberg et al (22) reported that Ap53Ab seropositivity was not dependent on histological grade, T-category or Union for International Cancer Control stage. Gottschlich et al (23) also reported that there was no correlation between Ap53Ab status and clinical characteristics. By contrast, Porrini et al (35) reported that Ap53Ab may be associated with histopathological tumor grade, localization and recurrence. In addition, Chow et al (26) reported a positive correlation between Ap53Ab positivity and the frequency of nodal metastasis. Yamazaki et al (27) demonstrated that Ap53Ab status was significantly associated with secondary neck metastasis. In the present study, the Ap53Ab status exhibited a significant association with tumor size, lymph node metastasis and pathological stage. In particular, the frequency of cases in the pathological N-category was higher in the Ap53Ab-positive group compared with that in the Ap53Ab-negative group (Table III). Recently, Sano et al (36) reported that the TP53 mutation was associated with aggressive malignant behavior in head and neck SCC, including OSCC. Taken together, the findings of previous studies as well as the present study suggest that the presence of Ap53Ab in the serum may indicate the presence of TP53 mutations in the primary tumor, which is accompanied by aggressive malignant phenotypes, such as enhanced proliferation, invasion and metastatic potential, acquired by tumor cells.

Studies have reported that a positive Ap53Ab status was associated with a poor prognosis in patients with various malignancies, such as colorectal, esophageal, breast and oral cancer $(11,27,37,38)$. In line with previous reports, we herein observed a significant association between Ap53Ab status and prognosis, particularly in terms of DFS (Fig. 3A). Indeed, a positive association between positive Ap53Ab status and poor DFS was observed. Moreover, positive Ap53Ab status was identified as one of the independent prognostic factors in this study (Fig. 3A; Table IV). The reason for these results may be associated with the tendency for aggressive malignant phenotypes to be more frequent in Ap53Ab-positive patients (Table III). Furthermore, as the positive rate of Ap53Ab tended to be high, not only in cases with pathological lymph node metastasis, but also in cases with delayed neck metastasis, Ap53Ab may be a potential predictive marker for occult neck metastasis in patients with OSCC. Cumulatively, our data indicate that $\mathrm{Ap} 53 \mathrm{Ab}$ status may serve as a biomarker for predicting the prognosis of patients with OSCC in terms of DFS. In support of this hypothesis, Ushigome et al (5) recently reported the usefulness of perioperative monitoring of tumor markers (including Ap53Ab) in colorectal cancer. Therefore, we are currently in the process of starting a prospective observational study to measure the levels of Ap53Ab and SCC Ag, a typical OSCC tumor marker, over time, in order to further elucidate their clinical significance in OSCC.

In conclusion, despite the limitations due to the small number of cases and the lack of tumor markers to compare, to the best of our knowledge, the present study is the first to re-evaluate the clinical significance of Ap53Ab in OSCC according to the current daily clinical practice in Japan, in order to further determine its potential usefulness.

\section{Acknowledgements}

The authors would like to thank Enago (www.enago.jp) for the English language review.

\section{Funding}

Financial support for the research, authorship and/or publication of this article was provided by a Grant-in-Aid for Scientific Research (C) (grant no. 18K09771) from the Japanese Ministry of Education, Culture, Sport, Science and Technology.

\section{Availability of data and materials}

The datasets generated and/or analyzed in this study are not publicly available due to privacy, but they are available from the corresponding author on reasonable request.

\section{Authors' contributions}

Conceptualization, SG and RY; methodology, KY; software, $\mathrm{HA}$; validation, $\mathrm{KY}$, SK and $\mathrm{YN}$; formal analysis, MN; investigation, AHiro HNakas; resources, AHira, KK; data curation, $\mathrm{RY}$; writing-original draft preparation, $\mathrm{SG}$; writing-review and editing, RY; visualization, JS; supervision, HidN; project administration, HNakay; funding acquisition, RY. SG and RY have seen and can confirm the authenticity of all the raw data. All the authors have read and approved the final version of the manuscript.

\section{Ethics approval and consent to participate}

The present study was conducted with the approval of the Ethics Committee of Kumamoto University (approval no. RINRI:1427), in accordance with the guidelines for Good Clinical Practice and the Declaration of Helsinki. The present study is a retrospective analysis, which does not require individual consent; however, it guarantees the participation in the study and offers the opportunity to refuse participation in an opt-out format (RINRI1427).

\section{Patient consent for publication}

Not applicable.

\section{Competing interests}

The authors declare that they have no competing interests. 


\section{References}

1. Siegel RL, Miller KD and Jemal A: Cancer statistics, 2017. CA Cancer J Clin 67: 7-30, 2017.

2. Krimmel M, Hoffmann J, Krimmel C, Cornelius CP and Schwenzer N: Relevance of SCC-Ag, CEA, CA 19.9 and CA 125 for diagnosis and follow-up in oral cancer. J Craniomaxillofac Surg 26: 243-248, 1998.

3. Soussi T: p53 antibodies in the sera of patients with various types of cancer: A review. Cancer Res 60: 1777-1788, 2000.

4. Lubin R, Schlichtholz B, Teillaud JL, Garay E, Bussel A and Wild CP: p53 antibodies in patients with various types of cancer: Assay, identification, and characterization. Clin Cancer Res 1: 1463-1469, 1995.

5. Ushigome M, Shimada H, Miura Y, Yoshida K, Kaneko T, Koda T, Nagashima Y, Suzuki T, Kagami S and Funahashi K: Changing pattern of tumor markers in recurrent colorectal cancer patients before surgery to recurrence: Serum p53 antibodies, CA19-9 and CEA. Int J Clin Oncol 25: 622-632, 2020.

6. Couch ME, Ferris RL, Brennan JA, Koch WM, Jaffee EM, Leibowitz MS, Nepom GT, Erlich HA and Sidransky D: Alteration of cellular and humoral immunity by mutant p53 protein and processed mutant peptide in head and neck cancer. Clin Cancer Res 13: 7199-7206, 2007.

7. Shimada H, Ochiai T and Nomura F; Japan p53 Antibody Research Group: Titration of serum p53 antibodies in 1,085 patients with various types of malignant tumors: A multiinstitutional analysis by the Japan p53 antibody research group. Cancer 97: 682-689, 2003.

8. Ralhan R, Agarwal S, Nath N, Mathur M, Wasylyk B and Srivastava A: Correlation between p53 gene mutations and circulating antibodies in betel- and tobacco-consuming North Indian population. Oral Oncol 37: 243-250, 2001.

9. Sainger RN, Shah MH, Desai AA, Shukla SN, Shah PM, Telang SD and Patel PS: Clinical significance of serum p53 antibodies in oral cancer. Tumori 92: 134-139, 2006.

10. Okada R, Otsuka Y, Wakabayashi T, Shinoda M, Aoki T, Murakami M, Arizumi S, Yamamoto M, Aramaki O, Takayama T, et al: Six autoantibodies as potential serum biomarkers of hepatocellular carcinoma: A prospective multicenter study. Int J Cancer 147: 2578-2586, 2020.

11. Takashi S, Satoshi Y, Akihiko O, Naoya Y, Yusuke T, Kentaro M, Yu O, Yasuaki N, Koichi Y, Takashi F, et al: Clinical impact of preoperative serum p53 antibody titers in 1487 patients with surgically treated esophageal squamous cell carcinoma: A multi-institutional study. Esophagus 18: 65-71, 2021.

12. Oshima Y, Suzuki T, Yajima S, Nanami T, Shiratori F, Funahashi K and Shimada H: Serum p53 antibody: Useful for detecting gastric cancer but not for predicting prognosis after surgery. Surg Today 50: 1402-1408, 2020

13. Zhou G, Liu Z and Myers JN: TP53 mutations in head and neck squamous cell carcinoma and their impact on disease progression and treatment response. J Cell Biochem 117: 2682-2692, 2016.

14. Amin MB, Edge S, Greene F, Byrd DR, Brookland RK, Washington MK, Gershenwald JE, Compton CC, Hess KR, Sullivan DC, et al (eds): AJCC Cancer Staging Manual. 8th edition. Springer International Publishing, New York, NY, 2017.

15. El-Naggar AK, Chan JC, Grandis JR, Takata T, Grandis J and Slootweg P (eds): WHO Classification of Head and Neck Tumours. 4th edition. IARC, Lyon, 2017.

16. Nasierowska-Guttmejer A, Trzeciak L, Nowacki MP and Ostrowski J: p53 protein accumulation and p53 gene mutation in colorectal cancer. Pathol Oncol Res 6: 275-279, 2000.

17. Bertorelle R, Esposito G, Belluco C, Bonaldi L, Del Mistro A, Nitti D, Lise M and Chieco-Bianchi L: p53 gene alterations and protein accumulation in colorectal cancer. Clin Mol Pathol 49: M85-M90, 1996.

18. Poeta ML, Manola J, Goldwasser MA, Forastiere A, Benoit N, Califano JA, Ridge JA, Goodwin J, Kenady D, Saunders J, et al: TP53 mutations and survival in squamous-cell carcinoma of the head and neck. N Engl J Med 357: 2552-2561, 2007.

19. Bourhis J, Lubin R, Roche B, Koscielny S, Bosq J, Dubois I, Talbot M, Marandas P, Schwaab G, Wibault P, et al: Analysis of p53 serum antibodies in patients with head and neck squamous cell carcinoma. J Natl Cancer Inst 88: 1228-1233, 1996.

20. Maass JD, Gottschlich S, Goeroegh T, Lippert BM and Werner JA: Head and neck cancer and p53-immunogenicity. Anticancer Res 17: 2873-2874, 1997.
21. Werner JA, Gottschlich S, Folz BJ, Goeroegh T, Lippert BM, Maass JD and Rudert H: p53 serum antibodies as prognostic indicator in head and neck cancer. Cancer Immunol Immunother 44: 112-116, 1997.

22. Wollenberg B, Jan NV, Pitzke P, Reiter W and Stieber P: Anti-p53 antibodies in serum of smokers and head and neck cancer patients. Anticancer Res 17: 413-418, 1997.

23. Gottschlich S, Folz BJ, Goeroegh T, Lippert BM, Maass JD and Werner JA: A new prognostic indicator for head and neck cancer-p53 serum antibodies? Anticancer Res 19: 2703-2705, 1999.

24. Gottschlich S, Maune S, Maass JD, Görögh T, Hoffmann M, Hoffmann-Fazel A, Meyer J, Werner JA and Rudert H: Serum p53 autoantibodies in the follow-up of head and neck cancer patients. Oncology 59: 31-35, 2000.

25. Warnakulasuriya S, Soussi T, Maher R, Johnson N and Tavassoli M: Expression of p53 in oral squamous cell carcinoma is associated with the presence of $\operatorname{IgG}$ and $\operatorname{IgA}$ p53 autoantibodies in sera and saliva of the patients. J Pathol 192: 52-57, 2000.

26. Chow V, Yuen AP, Lam KY, Ho WK and Wei WI: Prognostic significance of serum p53 protein and p53 antibody in patients with surgical treatment for head and neck squamous cell carcinoma. Head Neck 23: 286-291, 2001.

27. Yamazaki Y, Chiba I, Ishikawa M, Satoh C, Notani K, Ohiro Y, Totsuka Y, Mizuno S and Kitagawa Y: Serum p53 antibodies as a prognostic indicator in oral squamous cell carcinoma. Odontology 96: 32-37, 2008.

28. Takahashi R, Sakamoto K, Sugimoto K, Motegi S, Tsukamoto R, Ichikawa R, Okazawa Y, Aoki J, Ishiyama S, Takahashi M, et al: Significance of serum p53 antibody as a tumor marker in colorectal cancer. Dis Markers 2019: 2721876, 2019.

29. von Brevern MC, Hollstein MC, Cawley HM, De Benedetti VM, Bennett WP, Liang L, He AG, Zhu SM, Tursz T, Janin N and Trivers GE: Circulating anti-p53 antibodies in esophageal cancer patients are found predominantly in individuals with p53 core domain mutations in their tumors. Cancer Res 56: 4917-4921, 1996.

30. Davidoff AM, Iglehart JD and Marks JR: Immune response to p53 is dependent upon p53/HSP70 complexes in breast cancers. Proc Natl Acad Sci USA 89: 3439-3442, 1992.

31. Schlichtholz B, Legros Y, Gillet D, Gaillard C, Marty M, Lane D, Calvo F and Soussi T: The immune response to p53 in breast cancer patients is directed against immunodominant epitopes unrelated to the mutational hot spot. Cancer Res 52: 6380-6384, 1992.

32. George B, Datar RH, Wu L, Cai J, Patten N, Beil SJ, Groshen S, Stein J, Skinner D, Jones PA, et al: p53 gene and protein status: The role of $\mathrm{p} 53$ alterations in predicting outcome in patients with bladder cancer. J Clin Oncol 25: 5352-5358, 2007.

33. Dix B, Robbins P, Carrello S, House A and Iacopetta B: Comparison of p53 gene mutation and protein overexpression in colorectal carcinomas. Br J Cancer 70: 585-590, 1994.

34. Yemelyanova A, Vang R, Kshirsagar M, Lu D, Marks MA, Shih IeM and Kurman RJ: Immunohistochemical staining patterns of p53 can serve as a surrogate marker for TP53 mutations in ovarian carcinoma: An immunohistochemical and nucleotide sequencing analysis. Mod Pathol 24: 1248-1253, 2011.

35. Porrini R, Vercellino V, Rocchetti V, Renò F, Giorda E, Pomato E, Cannas M and Sabbatini M: Serum anti-p53 antibodies as a diagnostic tumor marker: Observations in patients with malignant and premalignant oral cavity lesions. Minerva Stomatol 59: 233-243, 2010.

36. Sano D, Xie TX, Ow TJ, Zhao M, Pickering CR, Zhou G, Sandulache VC, Wheeler DA, Gibbs RA, Caulin C and Myers JN: Disruptive TP53 mutation is associated with aggressive disease characteristics in an orthotopic murine model of oral tongue cancer. Clin Cancer Res 17: 6658-6670, 2011.

37. Yamaguchi T, Takii Y and Maruyama S: Usefulness of serum p53 antibody measurement in colorectal cancer: An examination of 1384 primary colorectal cancer patients. Surg Today 44: 1529-1535, 2014.

38. Sirotković-Skerlev M, Plavetić ND, Sedlić F, Kuna SK, Vrbanec D, Belev B, Pleština S, Kovač Z and Kulić A: Prognostic value of circulating Bcl-2 and anti-p53 antibodies in patients with breast cancer: A long term follow-up (17.5 years). Cancer Biomark 30: 95-104, 2021.

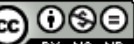

This work is licensed under a Creative Commons Attribution-NonCommercial-NoDerivatives 4.0 International (CC BY-NC-ND 4.0) License. 